\title{
Sharing What we Know About Living a Good Life: Indigenous Approaches to Knowledge Translation
}

\author{
Janet Smylie, Michelle Olding, and Carolyn Ziegler
}

\begin{abstract}
Knowledge Translation (KT), a core priority in Canadian health research, policy, and practice for the past decade, has a long and rich tradition within Indigenous communities. In Indigenous knowledge systems the processes of "knowing" and "doing" are often intertwined and indistinguishable. However, dominant KT models in health science do not typically recognize Indigenous knowledge conceptualizations, sharing systems, or protocols and will likely fall short in Indigenous contexts. There is a need to move towards KT theory and practice that embraces diverse understandings of knowledge and that recognizes, respects, and builds on pre-existing knowledge systems. This will not only result in better processes and outcomes for Indigenous communities, it will also provide rich learning for mainstream KT scholarship and practice. As professionals deeply engaged in KT work, health librarians are uniquely positioned to support the development and implementation of Indigenous KT. This article provides information that will enhance the ability of readers from diverse backgrounds to promote and support Indigenous KT efforts, including an introduction to Indigenous knowledge conceptualizations and knowledge systems; key contextual issues to consider in planning, implementing, or evaluating KT in Indigenous settings; and contemporary examples of Indigenous KT in action. The authors pose critical reflection questions throughout the article that encourage readers to connect the content with their own practices and underlying knowledge assumptions.
\end{abstract}

\section{Introduction}

The emergence of Knowledge Translation (KT) as a health research, policy, and practice priority in Canada is strongly linked to the creation and initial mandate of the Canadian Institutes of Health Research (CIHR) in 2000. This initial aim of the CIHR was to excel not only in the creation of new knowledge but also to ensure that this knowledge was "translated" from the research setting into "real-world applications to improve the health of Canadians, provide more effective health services and products, and strengthen the health care system" $[1,2]$. The CIHR originally defined $\mathrm{KT}$ as "the exchange, synthesis and ethically sound application of knowledge-within a complex system of interactions among researchers and users - to accelerate the capture of the benefits of research for Canadians through improved health, more effective services and products, and a strengthened health care system" [2].

In subsequent years, definitions and models of KT have expanded rapidly, extending from research-embedded conceptualizations to program- and service-based activities [3].
There is currently no clear consensus in the literature regarding what $\mathrm{KT}$ is and which models and strategies are the most effective. There is some convergence in the recent literature about the effectiveness of participatory KT processes that attempt to understand and address the context in which $\mathrm{KT}$ is taking place and to bridge some type of "know-do gap" [4]. Health librarians have highlighted the critical role existing human information services (i.e., reference librarians, pharmacists, patient education specialists) already play in linking knowledge sources to knowledge users and the synergies that can be gained by building on and expanding these roles [3].

Indigenous scholars and communities across Canada have been active - if at times reluctant-participants in this burgeoning KT movement, working to ensure that Indigenous people, their needs, and their potential contributions were taken into account [5]. The lead author (JS) has had the opportunity to be involved in bridging conversations regarding KT and Indigenous community knowledge systems since the initial CIHR consultations including a CIHR led KT workshop in June 2002 and early funding initiatives. Ironically, a common initial response

Janet Smylie. ${ }^{1}$ Well Living House, Centre for Research on Inner City Health, Li Ka Shing Knowledge Institute; Dept. of Family and Community Medicine, St. Michael's Hospital, 30 Bond Street, Toronto, ON M5B 1W8 and Dalla Lana School of Public Health, University of Toronto, Toronto, ON.

Michelle Olding. Dalla Lana School of Public Health, Toronto, ON.

Carolyn Ziegler. Health Sciences Library, Li Ka Shing International Healthcare Education Centre at St. Michael's Hospital, 209 Victoria Street, 3rd Floor, Toronto, ON M5B 1T8, Canada.

${ }^{1}$ Corresponding author (e-mail: janet.smylie@utoronto.ca) 
when she started talking about $\mathrm{KT}$ in diverse Indigenous communities was that mainstream conceptualizations of KT were hard to make sense of and did not appear to be practically relevant. As the conversations deepened it became evident that KT was nothing new for Indigenous peoples. In contrast to the evolution of European knowledge and knowledge systems that has resulted in a separation of knowledge production from knowledge use, in Indigenous contexts knowledge is almost always inextricable linked to action both philosophically and practically.

There are distinct understandings of knowledge and unique, diverse, and contextually specific knowledge sharing processes found in Indigenous communities. Ideally, efforts to support $\mathrm{KT}$ in Indigenous contexts would build on local Indigenous languages and existing knowledge conceptualizations, sharing systems and protocols. Indigenous communities have identified a strong preference for approaches to KT that draw on Indigenous ways of knowing and doing [5-7]. Such approaches have also been demonstrated to be practically effective across diverse Indigenous communities [8]. These demonstrations build on the much broader literature regarding the importance of knowledge, attitudes, and beliefs to health learning and behaviour change. Clearly, messages, mediums, and practices that demonstrate socio-cultural congruency (i.e., draw on local cultural knowledge, attitudes, and belief systems) will have better uptake. This is especially important for Indigenous people and communities where a big part of colonial policy has been premised on the marginalization and devaluing of Indigenous ways of knowing and doing [9].

Our aim in this article is to provide relevant information that will enhance the ability of readers from diverse backgrounds to promote and support Indigenous KT efforts (i.e., KT processes that build on Indigenous understandings of knowledge and Indigenous approaches to knowledge sharing). Each section features critical reflection questions that we hope will challenge the reader to bridge the content of this article to their own underlying knowledge assumptions and practices.

\section{Indigenous knowledge(s), knowledge systems, and $\mathrm{KT}$}

Critical reflection questions: What assumptions do I make about what constitutes valid and useful knowledge? How do these assumptions fit or not fit with the ideas about Indigenous knowledge and knowledge systems described in this section?

As alluded to above, KT scholarship and practice in Canada has emerged within the context of university- and hospital-based health sciences research, a knowledge system in which the domains of research and action-practice have largely been kept separate [10]. It is important to recognize that Indigenous knowledge systems and KT practices are rooted in a very different linguistic, cultural, social, political, and historic context. Not surprisingly given these differences, mainstream KT theoretical models and proven practices may fall short in Indigenous contexts.
Understanding the differences and similarities in the root epistemologies of academic health sciences and Indigenous community knowledge systems is a key step in supporting the development and implementation of KT strategies that are relevant and useful to Indigenous peoples. An epistemology is a theory of knowledge that sets out what constitutes knowledge and how we come to know. Academic health sciences have emerged from positivist thought traditions in which the goal of knowledge production is to search for general laws or principles through "objective" observation. Within the positivist tradition, knowledge is that which can be quantified and counted and is thought to exist independent of the people or places from which it emerges [11]. Health sciences knowledge production is characterized by knowledge specialization and academic silos, meaning that $\mathrm{KT}$ is typically conceptualized as the translation of expert knowledge from researcher to health care practitioners [10].

Indigenous knowledge systems have underlying epistemologies that are distinct from those of academic health sciences [12, 13]. Indigenous epistemologies, for example, almost always intrinsically connect knowledge with action. For an individual to hold knowledge and not apply it in their life or share it for the benefit of the collective could be seen as foolish and selfish from an Indigenous perspective. Knowledge may be considered as pre-existing such that there are no new "discoveries" but rather a process of gradual awareness and understanding of complex, interconnected, and pluralistic systems of existing knowledge. In this way, knowledge development work is actively transformative as it is linked to life-long processes of human development. Stories themselves can be perceived as holding "medicine" and the process of sharing stories as acts of healing.

Another foundational element of many Indigenous knowledge systems is that the inter-relationships between perceived elements are considered equally or more important than the nature of the perceived elements themselves. For example, in considering physical health, it would be important to consider not only physical health alone but also physical health in relation to mental, emotional, and spiritual health; family, community, nation; land and the local eco-system; and kin relations past, present, and future.

The importance of inter-relationality extends to the conceptualization of the individual in relation to the collective. For many Indigenous people, notions of identity, health, rights, and freedoms are rooted in the collective. The health needs of the family or community may take precedence over individual health needs. Likewise land, material goods, or information may be seen as primarily a collective rather than individual resource. This contrasts with euro-western concepts of self and individual rights and freedoms [14].

With these considerations in mind, $\mathrm{KT}$ in Indigenous contexts could be understood as "Indigenously led sharing of culturally relevant and useful health information, and practices to improve Indigenous health status, policy, services, and programs" [15] or more simply as "Sharing what we know about living a good life" [15]. Indigenous processes of sharing and applying knowledge 
have always been an essential and embedded part of Indigenous civilizations [16]. Indigenous KT strategies and protocols are commonly dynamic, participatory, integrated into family and community activities, repeated or cyclical, and intergenerational [15]. A reliance on the land for sustenance translated into the need for sophisticated understandings of and relationships with local ecosystems. As such, experiential demonstration and practice in real life situations were common Indigenous KT approaches for this type of knowledge [15-17]. Storytelling is another core Indigenous KT strategy, particularly common for the intergenerational transfer of knowledge.

It is important to keep in mind that in this section we introduced only a few overly simplified characteristics of Indigenous knowledge, knowledge systems, and KT. The actual diversity and complexity of Indigenous knowledge could be paralleled to the diversity and complexity of the vast landscapes of the Americas (to which it is heavily tied). There is no one-size-fits-all model for what $\mathrm{KT}$ should look like, given the diversity of knowledge sharing practices across communities. Likewise, our portrayal of academic health sciences has not included the modern and post-modern integration of social sciences and the increasingly complex interdisciplinary paradigms currently in use. Our comparisons have highlighted tensions because knowing and understanding difference can be a useful starting point in contexts where differences have been previously ignored or overlooked. However, although Western and Indigenous systems of knowledge and knowledge dissemination have many differences, the two are not entirely irreconcilable [18].

Currently though, most health science KT efforts have been modelled on the one-way transfer of academic health knowledge into Indigenous communities, often with little consideration of pre-existing Indigenous knowledge systems. This external imposition of one knowledge system onto another, although often done with good intentions, is almost always ineffective, especially when there are key theoretical and practical tensions. Indigenous scholar and elder Leroy Littlebear described this process as "jagged worldviews colliding" [19]. For Indigenous individuals and communities, such one-way KT processes may resonate with historic and current colonial practices such as the apprehension of Indigenous children into residential schools, where there was a subsequent one-way transfer of European-based language and schooling or the imposition of European systems of law and land rights into Indigenous communities through the Indian Act and other colonial legislations. The fundamental rights of Indigenous self-determination at the individual and collective levels include not only land rights but also the right to "construct knowledge in accordance with self-determined definitions of what is real and what is valuable" [14]. The development and application of Indigenous KT models is therefore not only practical but also integral to processes of decolonization and healing.

Moving towards KT models that embrace diverse understandings of knowledge and recognize, respect, and build on existing knowledge systems will not only result in better processes and outcomes for Indigenous communities, it will also provide rich learning for mainstream KT scholarship and practice. In the following section we will examine some key contextual issues that should inform the development of KT strategies in Indigenous settings. Keep in mind that many of these issues may also be relevant more broadly.

\section{Important contextual issues to consider when planning, implementing, and (or) evaluating knowledge sharing activities in Indigenous contexts}

Critical reflection questions: What do you know about the Indigenous peoples and communities in the geographic area where you live and work? From what sources is this knowledge drawn? Can you identify knowledge gaps and strategies to address these gaps in your personal understanding and knowledge? Which of the contextual issues listed do you think are relevant for your life and work with Indigenous individuals and communities? Which issues are relevant to your work more generally?

\section{Cultural safety}

There are many reasons why Indigenous community members may not feel comfortable or safe in nonIndigenous institutional contexts, including libraries. These can include historic and current individual and systemic level experiences of abuse, discrimination, and racism. The term "cultural safety" originated in New Zealand in response to dissatisfaction of Maori people with their nursing care. The nursing council of New Zealand had defined culturally unsafe care as "any actions that diminish, demean or disempower the cultural identity and wellbeing of an individual" [20]. The meaning and application of the term cultural safety is evolving in Canada; however, it is commonly perceived as an advancement beyond "cultural sensitivity" [21]. Cultural safety is usually defined by clients themselves, with the onus placed on health care professionals to self-reflect and work with their institution to address the impact of power imbalances, attitudinal, and institutional discrimination and colonization on service provision and client-provider relationships. This work can be particularly challenging given the pervasive negative representations of Indigenous people in the media and education systems.

\section{Underlying unmet material, social, and health needs}

The historic and current unequal distribution of health and social resources has translated into a disproportionate burden of poverty, food insecurity, homelessness and housing inadequacy, unemployment, and lower formal educational achievement for Indigenous people in Canada. Linked to these challenges in the social determinants of health are striking disparities in the health status of Indigenous peoples compared with the general Canadian population [22]. For example, diabetes and mental illness are much more common among First Nations populations compared with non-First Nations populations [23, 24]. It is important to understand that these unmet needs and high illness burdens can interfere with participation in learning, teaching, and participation in health information sharing events and programs. 


\section{Health literacy}

The Canadian Expert Panel on Health defines health literacy as "The ability to access, understand, evaluate and communicate information as a way to promote, maintain and improve health in a variety of settings across the lifecourse" [25]. Although little information regarding the health literacy of Indigenous peoples in Canada is available, we do know that this population faces a disproportionate burden of low literacy with respect to reading and writing in English compared with non-Indigenous communities as well as much lower rates of high school completion [26]. Indigenous-specific models of literacy also exist and are notable for their holistic understandings and approaches. The Rainbow/Holistic Approach to Aboriginal literacy, as one example, uses seven ways of knowing, each corresponding to a color and recognizes that spirit, heart, mind, and body equally contribute to a life of balance and nurtures them all [27].

\section{Protection and custodianship of Indigenous knowledge}

Colonization included the purposeful undermining of Indigenous languages and culture, commercialization of Indigenous art, and appropriation of Indigenous plant knowledge in the development of medicine, all without consent, acknowledgement, or benefit to Indigenous peoples [28]. Current legal regimes are still inadequate to protect Indigenous knowledge [28]. Within the context of Indigenous health and health information there are also examples of historic abuses and inequities in Canada, including nutritional experimentation on Indigenous children in residential schools and the exclusion of Indigenous communities from national health surveys. Not surprisingly given this history, many Indigenous communities are very concerned about external to community ownership, control, and access to and use of their health information and therefore have created policies and processes to ensure Indigenous governance and management of Indigenous health information [29].

\section{Publication bias}

The large majority of published health information has been created without taking Indigenous ways of knowing, doing, and sharing information into account. This literature is commonly perceived in Indigenous contexts as not immediately useful or relevant and, at worst, as a continuing colonial imposition of external ways of knowing upon Indigenous people. There is a deficit of Indigenous-led, Indigenous-authored, and community-relevant published materials. A large proportion of that which exists is in the form of "grey" literature (i.e., non-indexed publications). When Indigenous scholars and communities produce materials for non-Indigenous specific scholarly journals there is usually a tension between the defined criteria of what is acceptable in peer-reviewed publications and what might be perceived as relevant and linked to Indigenous ways of knowing and doing. This divergence means that articles that take Indigenous constructions of knowledge into account may be less likely to be published. For example, an editor may prioritize generalizability but Indigenous communities may want emphasis on the uniqueness of their particular context.

\section{Reciprocity in relationships}

Reciprocity is a foundational social and spiritual principle for many Indigenous communities that, according to Cree philosopher Willie Ermine, "dictat[es] how all life would co-exist in mutual protection, benefit, and continuity" [30]. Within the academic context this may emerge as a two-way teaching and learning process in which the dichotomy between "teacher" and "learner" is challenged, and the faculty members make extra efforts to be accessible and equally vulnerable in the knowledge relationship [31].

\section{Location}

A significant proportion of Indigenous people in Canada live in remote and rural areas where geographic location can limit access to infrastructure commonly taken for granted, such as high speed internet access, tertiary healthcare facilities, and public libraries. The majority of Indigenous people now live in urban areas in Canada and this population is rapidly increasing. Urbanization unfortunately does not necessarily translate into improved health or living conditions for Indigenous populations [23, 32, 33]. In cities, the Indigenous population may be more dispersed and diverse compared with more rural or remote settings.

Table 1 summarizes these specific strategies for implementing KT activities in Indigenous contexts.

\section{Indigenous knowledge translation in contemporary contexts-a few examples}

Critical reflection questions: Can you identify how these examples have incorporated Indigenous understanding of knowledge and Indigenous approaches to KT? Do they address the contextual issues identified in the previous section? Do you see them as valid examples of KT? Why or why not?

What follows is by no means meant to be comprehensive, we have simply selected a few examples from diverse settings. The lead author is currently in the process of building a more comprehensive listing of Indigenous KT initiatives that will be shared on an interactive web page. Please contact her if you have a good example that you would like to see included.

\section{Maria Campbell's Halfbreed Ball}

On 15 June 2013 as part of the Native American and Indigenous Studies Association Conference, held in Saskatoon, Saskatchewan, Métis elder, author, and community activist Maria Campbell organized an evening of food, dance, art, and entertainment. The Halfbreed Ball was fashioned on historic Métis social events that were held to honour the arrival and departure of visitors to Métis communities - times when the word Halfbreed was used with pride. The ten-course meal featured traditional foods served with a contemporary flair (Figure 1). Between courses, guests were treated to a parade of historic Métis fashion, poetry, fiddle music and jigging, and folk and opera singing. This was followed by an old-time dance. In the words of one guest "this evening. . .made abundantly clear the continuity of this lively culture and the warm, openhearted nature of those Métis well-grounded in and proudly contributing to the vitality of the culture today" (Susan 
Table 1. Contextual Issues for KT in Indigenous Contexts and Mitigating Strategies

Contextual issue

Cultural safety

Health literacy

Protection and custodianship of Indigenous knowledge

Underlying unmet material, social, and health needs

Publication bias

Reciprocity in relationships

Location
Mitigating Strategies

Critically reflect on your own knowledge, values, assumptions, and experiences generally with respect to the social hierarchies around class, age, ability, gender, sexual orientation, race and ethnicity, and more specifically with respect to Indigenous peoples.

We almost all have bias and prejudicial assumptions; can you identify any of yours? Are there particular populations groups where you are less knowledgeable, less comfortable, or more judgemental? How has the media and your education shaped your views?

Fill the gaps and (or) identify populations or groups for which you might need to do some more critical self-reflection to contribute to safe and respectful interactions.

Identify allies in your institution and within your communities of practice and work together to identify and address institutional barriers and increase institutional safety.

Search for institutional best practices that might be relevant to your place of work.

Learn more about Indigenous conceptualizations of literacy and health literacy [27].

Think broadly about literacy, (i.e., reading and writing in English is one aspect that is important in most mainstream institutional contexts) but what about the importance of traditional local ecologic literacies in a remote wilderness setting?

Strategize with others on how your institution could support diverse knowledge users to obtain an enhanced health literacy.

Co-create plain language summaries.

Assess and respond to opportunities to build capacity and literacy using health information technologies.

Critically examine information sources with an eye towards authenticity of authorship, Indigenous community involvement, and custodianship of Indigenous information and the prevention of appropriation.

Support and participate in processes that actively promote Indigenous community production and management of Indigenous health information and health information systems.

In situations where it appears a person external to the community is publishing or sharing Indigenous community health information with no apparent community involvement, ask questions.

Ensure that projects and events involving Aboriginal community members include budgets for transportation allowance and childcare. Provide healthy food at events and meetings. Ensure schedules fit with the needs of those who are experiencing chronic illnesses.

Allow for flexibility in scheduling to account for personal, family, and community illness or crisis.

Include grey literature and oral histories in your literature searches and indexes.

Recognize and value multiple forms of knowledge dissemination.

Consider incorporating equity criteria in your critical appraisal methods [34].

Be aware that search terms in use do not always match the terms by which Indigenous people self-refer; this can be problematic, both with the use of search terms that are considered offensive by some people (i.e., Indians, Eskimos) and also the non-specificity of terms now in more current use by Indigenous people (i.e., the term Indigenous).

Support Indigenous and community led publication efforts.

Ensure that the KT project or activity will be mutually beneficial to all parties, including Indigenous community partners.

For those in a role that may involve structured social privilege (i.e., health professional, librarian, academic faculty) make efforts to bridge relationships and build trust by sharing your own hopes, fears, and vulnerabilities in the learning relationship.

Create opportunities for Indigenous community capacity building and recognize that capacity building will be a two-way process (i.e., partners external to Indigenous community will also be gaining capacities and training in working with Indigenous communities).

When working with Indigenous peoples from a location that is different from where you live and work, ideally try and spend time in this place with a knowledgeable and willing community member who is being compensated for orienting you.

Working with Indigenous community partners, actively reflect on what is unique about the context and location where the KT activity is taking place.

Consider outreach strategies in urban areas. 
Fig. 1. Author Janet Smylie serving traditional food and Rajan Anderson playing fiddle at the Halfbreed Ball, Native American and Indigenous Studies Association conference, June 2013.

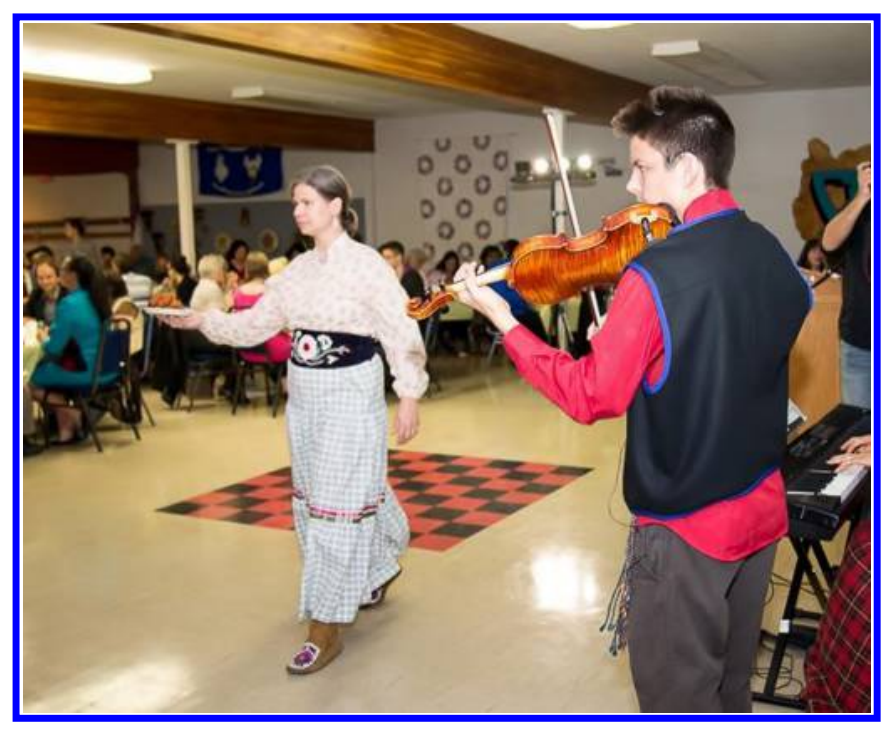

Gingell, written communication, 2013). This event exemplifies experiential, socially embedded Indigenous KT, which in this case showcased historic and contemporary Métis culture to Indigenous scholars from around the world.

\section{The Native Youth Sexual Health Network (NYSHN)}

The NYSHN is an organization engaged in KT around Indigenous youth sexual and reproductive well-being. Led by Indigenous youth, NYSHN encompasses a peer-based network of advocates, families, and communities [35]. The network collaborates on various initiatives that support Indigenous youth in sharing their own knowledge on healthy sexuality, as well as mobilizing collective action around youth-identified priorities. Some recent initiatives include a national gathering for Indigenous young women, a "sexy health" carnival, and a participatory action research project exploring the role of land in the sexual health of Metis women and youth [35]. KT, in this example, means building networks that support Indigenous youth in being both experts and knowledge users of sexual health information.

\section{Changing Climate, Changing Health, Changing Stories}

The Changing Climate, Changing Health, Changing Stories project provides a promising example of KT within a community-based research project. With funding from Health Canada's First Nations and Inuit Health Branch, the Rigolet Inuit Community Government formed a transdisciplinary team of Indigenous and non-Indigenous researchers to explore implications of climate change on physical, emotional, mental, and spiritual health [36, 37]. The project built from the rich oral tradition of Inuit knowledge systems by using digital storytelling and firstperson narratives as methods for exploring and sharing local experiences of climate change. Through a series of week-long workshops, community participants shared and developed personal stories, while receiving training to produce these narratives as a digital short that weaved their narrative with music, artwork, video clips, and photographs. KT occurred throughout the workshops as participants connected with themselves, their history, and the land through storytelling and dialogue. DVDs of the digital stories were made freely available to all participants and the community, and they were disseminated with permission of participants to policy makers and health professionals as well as posted online [36]. Perhaps most importantly, the project's investment in technology, infrastructure, and community training led to the development of the "My Word: Storytelling and Digital Media Lab", a community-run centre for digital media and research that continues to lead research in the community and the centre has expanded to offer a variety of research, media, and data-gathering services.

\section{Indigenous Knowledge Network for Infant, Child, and Family Health}

The Indigenous Knowledge Network for Infant, Child, and Family Health was a community partnered KT research project designed to support the gathering and application of Indigenous knowledge in 10 diverse First Nations, Métis, and urban Aboriginal communities. Ten frontline Aboriginal prenatal, infant, child, youth, and family health workers including midwives, health promotion program staff, health managers, and elders, were seconded to this project one day a week for four years. For the first two years they gathered oral histories from Indigenous elders and knowledge keepers in their communities of work. For the second two years they developed, implemented, and evaluated community-based knowledge application projects that drew on the Indigenous knowledge they had collected. The academic research team, based at the Well Living House Action Research Centre, supported program activities and facilitated network-wide meetings and interactions.

Evaluation of the network revealed very positive and transformative impacts for network participants, their clients, and the participant Aboriginal communities. Many of the knowledge application projects and relationships across the network and among network participants, community elders, and clients are ongoing. One of the keys to this project is that it actively builds on existing community resources and infrastructure. You can learn more about this project and the Well Living House Action Research Centre at http://www.stmichaelshospital.com/ crich/well-living-house/.

\section{Bridging Indigenous approaches to KT into health library science and practice}

It is our hope that readers will now be full of ideas and questions regarding the application of Indigenous KT approaches in their health information work and practice. We would like to remind you that it is very likely that you are already actively engaged in KT activities, some of which are synergistic with Indigenous $\mathrm{KT}$ ideas and protocols. In fact, almost everything that a health librarian does could be considered KT, especially if one draws on the Indigenous notions of KT as a sharing of knowledge that is bidirectional, participatory, and social. 
We have identified some specific strategies for implementing KT activities in Indigenous contexts in Table 1. More generally, it is our hope that readers will continue to think critically about their underlying assumptions regarding what is valid knowledge and what are valid knowledgesharing strategies - and be open to different ideas. In some instances health librarians will be able to build on what they are already doing. For example with respect to reciprocity in relationships, many librarians will recognize that in their day-to-day work they are already engaged in mutually beneficial bi-directional knowledge exchange as they are always learning something new and understanding information needs before proceeding with assisting users. In other cases, implementing some of the suggestions may be more challenging. For example, a health librarian who has focused on supporting research, policy, and practice users in acquiring "best evidence" using standardized critical appraisal methods drawn from clinical epidemiology may need to expand their knowledge regarding best evidence for Indigenous contexts and build new skills in identifying, critically appraising, and sharing materials drawn from grey literature and multimedia.

Health librarians may also find themselves in a position where they can facilitate a bridging of the knowledge and knowledge system gaps between researchers working with Indigenous communities and Indigenous communities themselves. There is already a within-discipline distinction between research KT and consumer health information. Indigenous $\mathrm{KT}$ approaches require an entry into and immersion in the knowledge and knowledge system of the "consumer," in this case the specific Indigenous individual or community in which the knowledge is to be applied. Also required is recognition that in passing through the doorway into an Indigenous knowledge system underlying assumptions from the outside may need to be revisited. For example, the assumption that health knowledge acquired through academic institutions will lead to more effective and higher quality health services for Indigenous peoples than knowledge derived from Indigenous peoples themselves or the assumption that research $\mathrm{KT}$ processes are completely distinct from the provision of consumer health information. For within an Indigenous context what might be most important with respect to research $\mathrm{KT}$ is helping the researcher understand the pre-existing health knowledge theories and practices of the Indigenous individual or community (i.e., the consumer).

For those who have already acquired knowledge and experiences regarding Indigenous approaches to knowledge and knowledge sharing, please share with others who have not had these opportunities through dialogue, training, and experiences. We would encourage each of you to build allegiances across Indigenous-non-Indigenous and community-academic divides. Critical self-reflection and communication regarding your own identity and intentions will support the building of allied relationships. Finally, when in doubt, ask. Find an Indigenous or allied colleague who has identified themselves as being available as a resource person and who you think may have the answer to your question or at least be able to direct you to the appropriate resource. Keep in mind the principles of mutual respect and reciprocity in your approach.
We have done our best in this article to share knowledge and resources to support readers interested in understanding and applying Indigenous approaches to KT. We recognize that some of the concepts, critical questions, strategies, and examples may be challenging for readers. However, we believe that much of the content is relevant not only to KT but also to other health and social science research, service, and policy work in Indigenous contexts. "New" ideas and strategies, such as KT, are constantly emerging in health and health information sciences. For example current CIHR strategies include terms such as "implementation science" and "evidence informed healthcare renewal". One commonality that will likely be shared by many of these future health science research and (or) practice directions is that they will exclude or marginalize Indigenous systems of knowledge and practice. A few, however, will realize the gains in both process and outcomes that can be made by keeping Indigenous ways of knowing and doing in mind - not only for Indigenous communities but for all peoples.

\section{References}

1. Government of Canada. Canadian Institutes of Health Research Act. S.C 2000, c. 6. Assented April 13, 2000. [Cited 21 January 2014]. Available from: http://laws-lois.justice.gc.ca/ eng/acts/C-18.1/.

2. Canadian Institutes of Health Research. Knowledge translation strategy 2004-2009: Innovation in Action. Canadian Institutes of Health Research. [Internet]. Ottawa: Canadian Institutes of Health Research; 2004 [Cited 18 January 2014]. Available from: http://www.cihr-irsc.gc.ca/e/26574.html.

3. Henderson J. Knowledge translation for Canadian health libraries: Finding our place between knowledge and its user. Paper presented at: Canadian Health Libraries Association Conference; 2011 May 29; Calgary. [Cited 18 January 2014]. Available from: http://www.chla-absc.ca/2011/node/161.

4. LaRocca R, Yost J, Dobbins M, Ciliska D, Butt M. The effectiveness of knowledge translation strategies used in public health: a systematic review. BMC Public Health. 2012;12:751.doi: 10.1186/1471-2458-12-751.

5. Wien F. A dance to create meaning together: perspectives on the ACADRE network on knowledge translation. [Internet]. AHRNet/NEAHR Resources; 2006 March 1. [Cited 21 January 2014] Available from: http://ahrnets.ca/files/2010/05/ A_Dance_to_Create_Meaning_March2006.pdf.

6. Ranford J, Warry W. Knowledge transfer/knowledge translation project summary report. [Internet]. AHRNet/NEAHR Resources; 2006 [Cited 21 January 2014]. Available from: http://ahrnets.ca/files/2010/05/IHRDP-Knowledge-TranslationSummary-Report-IHRDP.pdf.

7. Rikhy S, Jack M, Campbell L, Tough S. Knowledge exchange as a vehicle to improve the health of Aboriginal communities. Pimatisiwin. 2008;5(2):107-124.

8. Smylie J, Kaplan-Myrth N, McShane K. Indigenous knowledge translation: baseline findings in a qualitative study of the pathways of health knowledge in three indigenous communities in Canada. Health Promot.Pract. 2009;10(3):436-46. doi: $10.1177 / 1524839907307993$. 
9. Tuhiwai Smith L. Decolonizing methodologies: research and indigenous peoples. London: Zed Books; 1999.

10. Estey E, Smylie J, Maccauly A. Aboriginal knowledge translation: understanding and respecting the distinct needs of aboriginal communities in research. [Internet]. Canadian Institute for Health Research; 2009. [Cited 17 January 2014] Available from: http://www.cihr-irsc.gc.ca/e/41392.html.

11. Guba E, Lincoln, Y. Competing paradigms in qualitative research. In: Denzin NK, Lincoln YS, editors, Handbook of qualitative research. Thousand Oaks, CA: Sage; 1994. 105-117.

12. Ermine, W. Aboriginal epistemology. In: Battiste M, Barman J, editors, First Nations education in Canada: The circle unfolds. Vancouver: University of British Columbia Press; 1995. 101-112.

13. Little Bear L. Jagged worldviews colliding. In: Battiste M, editor, Reclaiming Indigenous voice and vision. Vancouver: University of British Columbia Press; 2000.

14. Brant Castellano M. Updating Aboriginal traditions of knowledge. In: Sefa Dei GJ, Hall BL, Rosenberg D, editors, Indigenous knowledges in global contexts. Toronto: University of Toronto Press; 2000. 21-36.

15. Kaplan-Myrth N, Smylie, J. Sharing what we know about living a good life. Summit report from the indigenous knowledge translation summit; 2006 March 2-5; Regina, SK. [Cited 18 January 2014]. Available from: http://iphrc.ca/ assets/Documents/Final_Summit_Report_Sept_30.pdf.

16. Smylie J. Knowledge translation and indigenous communities: a decolonizing perspective. In: Banister E, Leadbeater $\mathrm{B}$, Marshall A, editors. Knowledge translation in context. Toronto: University of Toronto Press; 2011.

17. Cajete G. Indigenous knowledge: the Pueblo metaphor of indigenous education. In: M Battise, editor, Reclaiming indigenous voice and wisdom. Vancouver: UBC Press; 2000. 181-208.

18. Estey E, Kmetic A, Reading, J. Knowledge translation in the context of Aboriginal Health. CJNR. 2008;40(2):24-49.

19. Little Bear L. Jagged worldviews colliding. In: Battiste M, editor, Reclaiming Indigenous voice and vision. Vancouver: University of British Columbia Press; 2000.

20. Nursing Council of New Zealand. Guidelines for cultural safety, the treaty of Waitangi, and Maori health in nursing and midwifery education and practice. Wellington: Nursing Council of New Zealand; 2002.

21. National Aboriginal Health Organization. Fact sheet; cultural safety. [Internet]. National Aboriginal Health Organization; 2006 January 31 [Cited 18 January 2014] Available from: http://www.naho.ca/documents/naho/english/Culturalsafetyfactsheet.pdf.

22. Adelson $\mathrm{N}$. The embodiment of inequity: health disparities in Aboriginal Canada. Can J Pub Health. 2005;96(S2):S46-S61.

23. Firestone M. Our health counts: Unmasking health and social disparities among urban Aboriginal people in Ontario. Toronto: University of Toronto; 2013.

24. Reading J. The crisis of chronic disease among Aboriginal people: A challenge for public health, population health and social policy. [Internet]. Victoria: University of Victoria
Centre for Aboriginal Health Research; 2009 [Cited 21 January 2014]. Available from: http://cahr.uvic.ca/docs/ ChronicDisease Final.pdf.

25. Rootman I, Gordon-El-Bihbety D. A vision for a health literate Canada. [Internet]. Ottawa: Canadian Public Health Association; 2008. [Cited 21 January 2014]. Available from: http://www.cpha.ca/uploads/portals/h-1/report_e.pdf.

26. Canadian Council on Learning. The state of Aboriginal learning in Canada: a holistic approach to measuring success. [Internet]. Ottawa: Canadian Council on Learning; 2009. [Cited 21 January 2014]. Available from: http://www.cclcca.ca/pdfs/StateAboriginalLearning/SAL-FINALReport_ EN.PDF.

27. George NP. The rainbow/holistic approach to aboriginal literacy. Canadian Journal of Native Education. 2003;27(1): $29-40$.

28. Battiste M, Youngblood Henderson JS. Protecting indigenous knowledge and heritage. Saskatoon: Purich Press; 2000.

29. First Nations Centre. OCAP: Ownership, control, access and possession. [Internet]. Sanctioned by the First Nations Information Governance Committee, Assembly of First Nations. Ottawa: National Aboriginal Health Organization; 2007 [Cited 31 January 2014]. Available from: http://cahr. uvic.ca/nearbc/documents/2009/FNC-OCAP.pdf

30. Ermine W. Cree Religious Ethos. [Internet]. University of Regina and Canadian Plains Research Centre; 2007 [Cited 21 January 2014]. Available from: http://esask.uregina.ca/entry/ cree_religious_ethos.html.

31. Kirkness V, Barnhardt R. First Nations and higher education: the four Rs - respect, relevance, reciprocity, responsibility. Journal of American Indian Education. 1991;30(3):1-15.

32. McCaskill D, FitzMaurice K, Cidro J. Toronto Aboriginal Research Project (TARP) Final Report.Toronto: Toronto Aboriginal Support Services Council; 2011.

33. Smylie J, Firestone M, Cochran L, Prince C, Maracle S, Moreley M, Mayo S, Spiller T, MacPherson B. Our health counts: community report. [Internet]. Toronto: Our Health Counts; 2011 [Cited 18 January 2014]. Available from: http://www.ourhealthcounts.ca/images/PDF/OHC-Report-Hamilton-ON.pdf.

34. Welch V, Petticrew M, O’Neill J, et al. Health Equity: Evidence synthesis and knowledge translation methods. Syst Rev. 2013;2:43.doi: 10.1186/2046-4053-2-43.

35. Native Youth Sexual Health Network. What we do. [Internet]. Native Youth Sexual Health Network website; 2014 [Cited January 2014]. Available from: http://www.nativeyouthsexualhealth.com/whatwedo.html.

36. Cunsolo Willox A, Harper S, Edge V. My Word: Storytelling and Digital Media Lab, Rigolet Inuit Community Government. Storytelling in a digital age: digital storytelling as an emerging narrative method for preserving and promoting indigenous oral wisdom. Qualitative Research. 2013;13(2): 127-147. doi: 10.1177/1468794112446105.

37. Harper SL, Edge VL, Cunsolo Willox A, Rigolet Inuit Community Government. "Changing climate, changing health, changing stories" profile: using an EcoHealth approach to explore impacts of climate change on inuit health. Ecohealth. 2012;9(1):89-101. doi: 10.1007/s10393-012-0762-x. 